\title{
Research Priorities for Addressing Gender Based Violence in the WHO Africa Region
}

\author{
Leopold Ouedraogo ${ }^{1 *}$, Triphonie Nkurunziza1, Assumpta Muriithi1, Bigirimana Françoise1, \\ Chilanga Asmani1, Hayfa Elamin1, Souleymane Zan1, Mihretu Belete1, Gbenou Dina1, \\ Dadji Kwami', Theopista Kabuteni John'1, Kim Caron Rahn², Ali Moazzam², Tolu Lemi², \\ Blami Dao ${ }^{3}$, Issiaka Sombie ${ }^{4}$, Okech Mollent ${ }^{5}$
}

\author{
${ }^{1}$ Reproductive, Maternal Health and Ageing, WHO Regional Office for Africa, Brazzaville, Congo \\ ${ }^{2}$ Department of Reproductive Health and Research, World Health Organization, Geneva, Switzerland \\ ${ }^{3}$ JHPIEGO, Ouagadougou, Burkina Faso \\ ${ }^{4}$ West Africa Health Organization, Ouagadougou, Burkina Faso \\ ${ }^{5}$ Peak Moments Global HR Solutions, Nairobi, Kenya \\ Email: `ouedraogol@who.int, nkurunzizat@who.int, kimca@who.int, alimoa@who.int, muriithia@who.int, bigirimanaf@who.int, \\ asmanic@who.int, elaminha@who.int, tolul@who.int, zans@who.int, tafesseb@who.int, gbenoud@who.int, dadjik@who.int, \\ kabutenit@who.int, blami.dao@jhpiego.org, isombie@wahooas.org, mollentakinyi@gmail.com
}

How to cite this paper: Ouedraogo, L., Nkurunziza, T., Mureithi, A., Françoise, B., Asmani, C., Elamin, H., Zan, S., Belete, M., Dina, G., Kwami, D., John, T.K., Rahn, K.C., Moazzam, A., Lemi, T., Dao, B., Sombie, I. and Mollent, O. (2021) Research Priorities for Addressing Gender Based Violence in the WHO Africa Region. Advances in Reproductive Sciences, 9, 50-59. https://doi.org/10.4236/arsci.2021.91006

Received: October 24, 2020

Accepted: December 28, 2020

Published: December 31, 2020

Copyright $\odot 2021$ by author(s) and Scientific Research Publishing Inc. This work is licensed under the Creative Commons Attribution International License (CC BY 4.0).

http://creativecommons.org/licenses/by/4.0/

(c) (i) Open Access

\begin{abstract}
Background: There is an increasing emphasis on conducting research to identify gender based violence issues to enable development of appropriate programs and interventions. However, these efforts are mixed in quality and often raise ethical questions. The increased pressure on policy makers to move to a more evidence-based approach in addressing gender based issues creates the need for this research prioritization activity. Inadequate evaluative evidence in this area poses a challenge in the planning for responsive interventions especially in resource limited settings. The purpose of this paper is to present gender based violence research priority areas for the WHO Africa Region. Methods: We utilized a modified version of the Child Health and Nutrition Research Initiative approach to reach consensus on research priorities on the thematic area of gender based violence. In three phases, we first conducted an online survey with sexual and reproductive health and rights experts in academia, ministries of health, non-governmental organizations and other health actors with a wide range of experiences. These questions were consolidated by three experts from World Health Organization headquarters into themes. Secondly, experts were invited in a meeting in Cape Town South Africa to analyze and generate relevant areas of research based on the themes. Finally, a smaller group of experts prioritized research areas based on agreed criteria. Results: A list of 10 priority research questions for addressing gender based violence were scored and ranked. Four priority re-
\end{abstract}


search questions scored 30 points out of the possible 30 points and were thus ranked as the highest priority. These included questions that "engage young adolescents in behavioral interventions to influence gender roles", "determinants of gender based violence analysis", "both long and short term complications of gender based violence on survivors" and "assessment of men's involvement in addressing gender-based violence against women". The second most highly ranked question was on the assessment of the extent and strategies to prevent gender-based violence in the context of humanitarian crises. Conclusions: Priority research questions for addressing gender based violence were identified. This exercise provides a three year investment case for research with high potential of effectively identifying interventions with high impact on addressing gender based violence.

\section{Keywords}

Gender-Based Violence, Gender, Human Rights, Sexual and Reproductive Health, Violence

\section{Introduction}

Gender based violence is a global problem with an estimated 1 in 3 women experiencing physical or sexual violence in their life time. This staggering number does not even account for psychological and emotional abuse [1]. Back in 1994, the International Conference on Population and Development (ICPD) approved a population development strategy focusing on sexual reproductive health and rights (SRHR) for all people but with an emphasis on women and adolescents. It further advocated for respectful rights and choices and gender equality, equity and empowerment of women to achieve progress. This approved Programme of Action was endorsed by all the United Nations member countries and it has guided the progress of SRHR for the last 25 years. They also served as the basis for the Millennium Development Goals [2].

In November, 2019 in the "ICPD+25 Nairobi Summit" on the $25^{\text {th }}$ Anniversary of the ICPD Programme of Action, the stakeholders gathered again to reflect on the progress made in advancing sexual reproductive health and to renew the commitments towards the achievement of sustainable development goals (SDGs) and to provide the best evidence and normative guidance for achieving sexual reproductive health and rights through universal health coverage [3]. A lot of significant successes have been achieved but more still needs to be done. For example, the number of sexually transmitted infections still remains high with more than one million infections occurring globally each day, a quarter million die yearly from cervical cancer and 1 in 3 women continue to be at risk of intimate partner on sexual violence during their life time [3].

Gender-based violence and sexual and reproductive health risks share a common root in gender inequality [4]. They include harmful practices within 
the SRH that constitute violence against women or girls, including forced sterilization and abortion, mistreatment of women/girls undergoing abortions, FGM/C and virginity testing. Intimate partner violence (IPV) has been shown to be a risk factor for diverse and severe physical and mental health consequences, including serious SRH consequences [5]. Many reproductive health conditions that affect the lives of women and girls are linked to GBV. GBV is increasingly viewed as a risk factor and a health problem by itself. Health consequences include injuries, gynaecological disorders, mental health problems, adverse pregnancy outcomes, and STIs [6].

The World Health Organization (WHO) in a multi-country study confirms a strong association between intimate partner violence (IPV) and many forms of poor health, including mental health and suicidal tendencies [7] [8] [9]. They identify the following costly health conditions to the health systems as associated with a "history of physical or sexual abuse": irritable bowel syndrome; sexually transmitted diseases; gastrointestinal disorders; gynaecological problems, including vaginal bleeding and vaginal infections; urinary tract infections; chronic pelvic pain; and serious mental health problems as depression, anxiety, post-traumatic stress disorder and risk of suicide.

Most of the GBV issues are mainly screened during the antenatal period when many of the women seek services. As well it has been associated with adverse pregnancy outcomes, such as low birth weight, premature labour, preterm delivery, miscarriage and foetal loss [10] [11] [12] [13]. This is a compelling rationale for the integration of GBV into SRHR activities like antenatal care. The linkages between GBV and SRH risks are bidirectional and the impact is devastating out lasting the physical injuries [14].

Integration of activities to address gender-based violence specifically violence against women and girls into sexual and reproductive health and rights (SRHR) services is critical to countries based on evidence. It is therefore against this background that WHO African Region conducted a research prioritization initiative adopting the Child Health and Nutrition Research Initiative (CHNRI) method to prioritize areas of concern in GBV in SRHR to assist policy makers, partners and stakeholders respond appropriately based on evidence.

\section{Methods}

This paper reports part of a larger research prioritization exercise conducted by the WHO African region in 2019. The paper focuses on prioritizing research questions that address gender based violence as part of the wider sexual and reproductive health and rights. The research prioritization exercise utilized the Child Health and Nutrition Research Initiative (CHNRI) methodology to reach consensus on priorities with a wide range of experts on SRHR. The approach used during the meeting to identify the research priorities followed a modified Child Health and Nutrition Research Initiative Approach (CHNRI). The overall process followed comprises of the following steps of gathering inputs from in- 
vestors/policy-makers (who define the context and the criteria for priority setting); and collecting further inputs from a larger group of technical experts (who propose, list systematically, and then independently score many research ideas) and also collecting inputs other stakeholders (who agree on differential weights for the chosen priority-setting criteria according to a wider societal system of values); and computation and discussion of the scores and analysis of the agreement between experts.

In three phases, we first conducted an online survey with sexual and reproductive health and rights experts in academia, ministries of health, non-governmental organizations and various health actors with a wide range of experiences in $\mathrm{Au}$ gust 2019. The prioritized questions were based on answerability, effectiveness, deliverability, equity and the capacity to potentially impact gender based programs. The questions were then reviewed and consolidated by experts from WHO headquarters into themes in September 2019. In the second phase of implementing the process, a total of 67 experts were invited in a meeting in Cape Town, South Africa from 29th October to 1st November, 2019. In groups the experts reviewed the list of 46 questions proposed from the online survey toughing on addressing gender based violence. The review ensured that the questions were researchable, had no duplications and had consistent wordings. The process resulted to identification of 25 main questions addressing gender based violence. In the final phase, a smaller group of experts scored and ranked the research priorities using the modified CHNRI methodology. The scoring criteria used are highlighted in Table 1. The lowest score was 1while the highest score was 5. Each question could therefore attain a lowest score of 6 or the highest score of 30 .

All the three phases and the activities of the process are summarized in Figure 1.

Table 1. Modified scoring criteria.

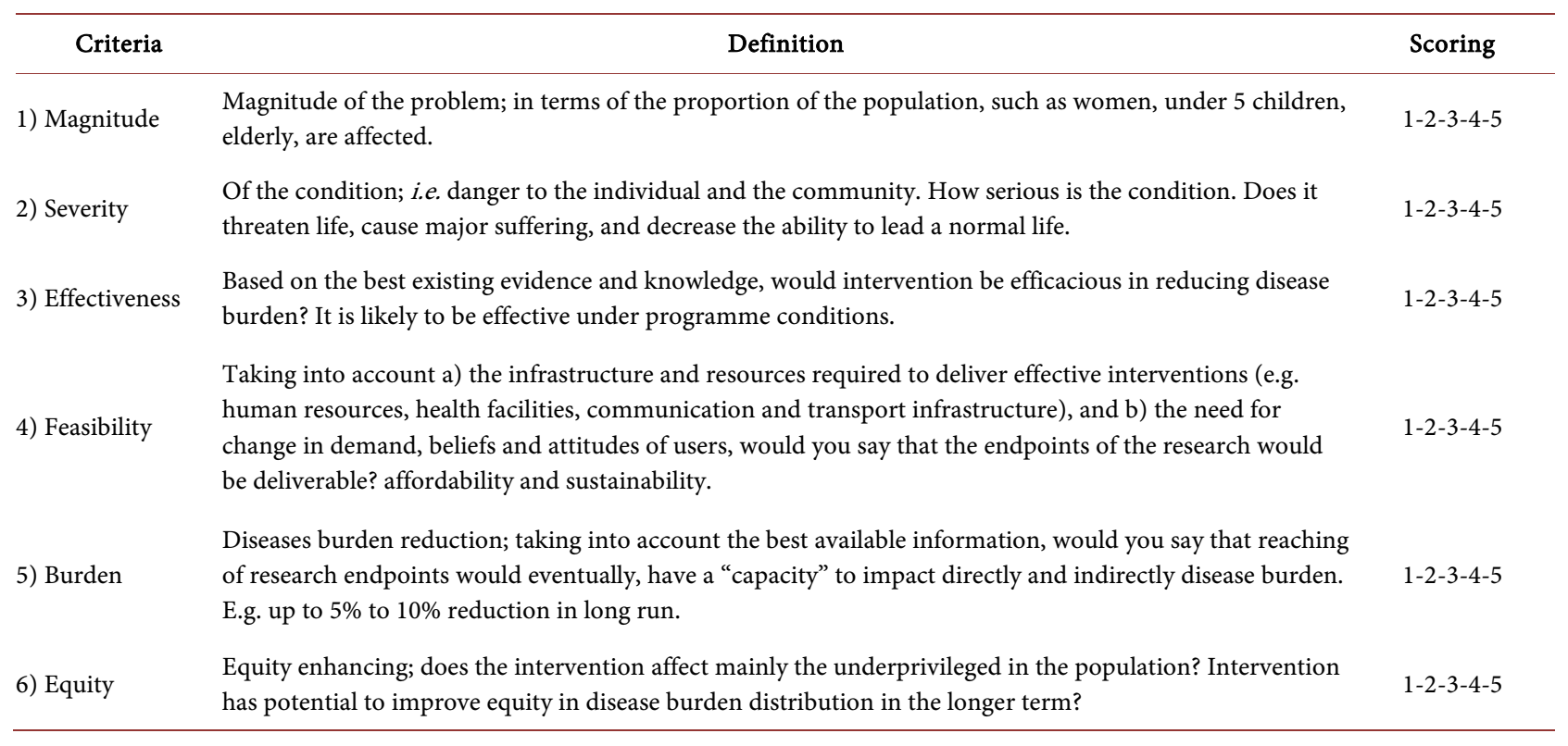




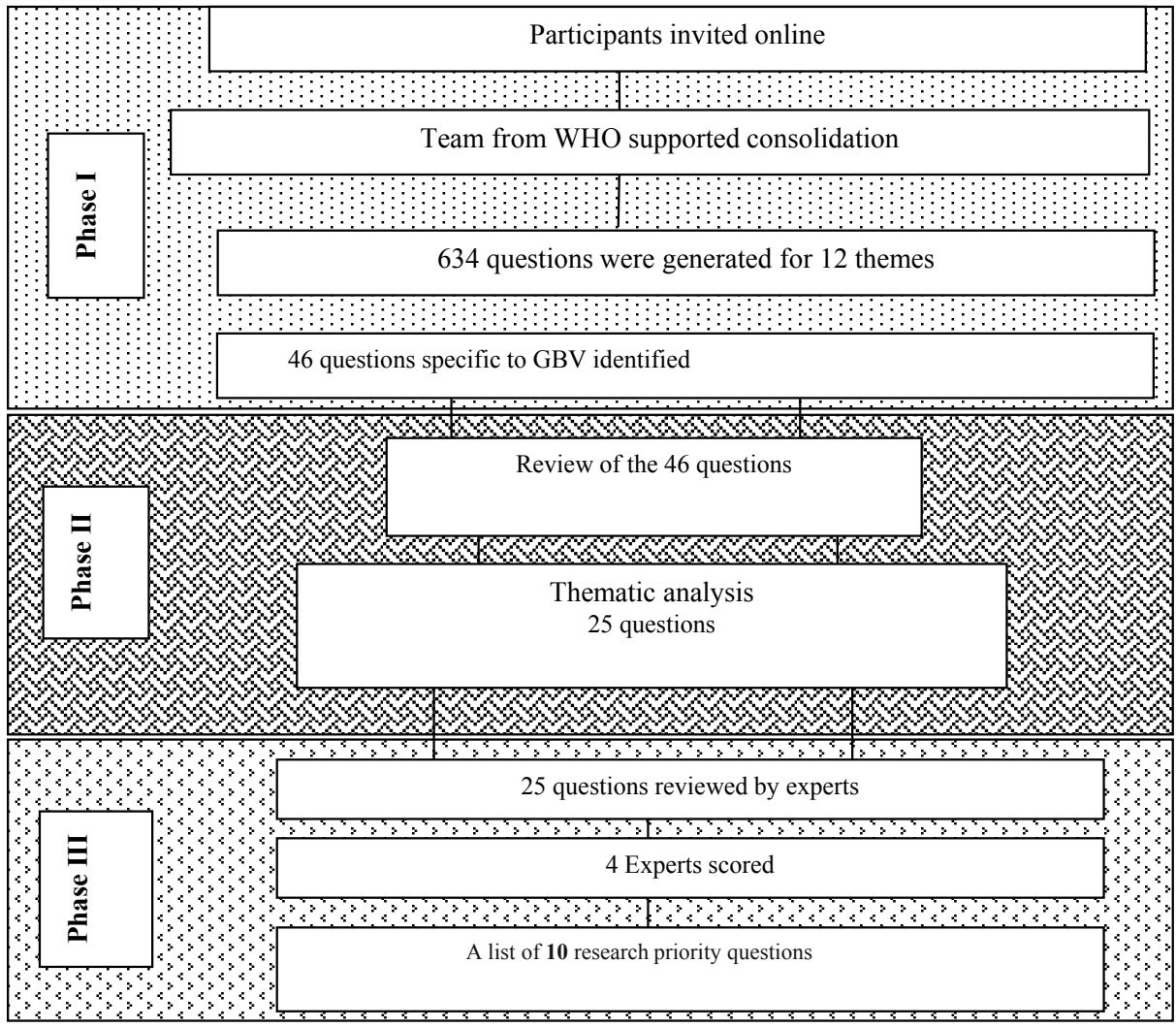

Figure 1. Summary of the study flow.

The scores from each-magnitude, severity, effectiveness, feasibility, burden and equity were summed up together to provide the total scores for each question. No special weighting was applied to the scoring criteria.

\section{Results}

In this paper, we report the identified research priorities on addressing gender based violence from the wider prioritization exercise. The top ten research priority questions according to the overall scores are presented in Table 2. Four questions were ranked the highest with the highest score of 30 points out of the possible maximum of 30 . These questions include; "involvement of young adolescents in behavioral interventions to influence gender roles using longitudinal prospective trials"; "analyzing determinants of gender-based violence-female genital mutilation(FGM), early marriages, pedophilia, domestic and sexual violence"; "short and long term complications of GBV among survivors" and "assessing the effectiveness of men's involvement in addressing gender-based violence against women".

The second most highly ranked question was on "assessment of the extent and strategies to prevent gender based violence in the context of humanitarian crisis" at 28 points, another set of 4 research questions were all scored at 27 points and they include; "Attitudes and perceptions of the community (civil society, associations, political leaders, religious and customary leaders) and health providers 
Table 2. Scoring of the top ten research priorities in gender based violence.

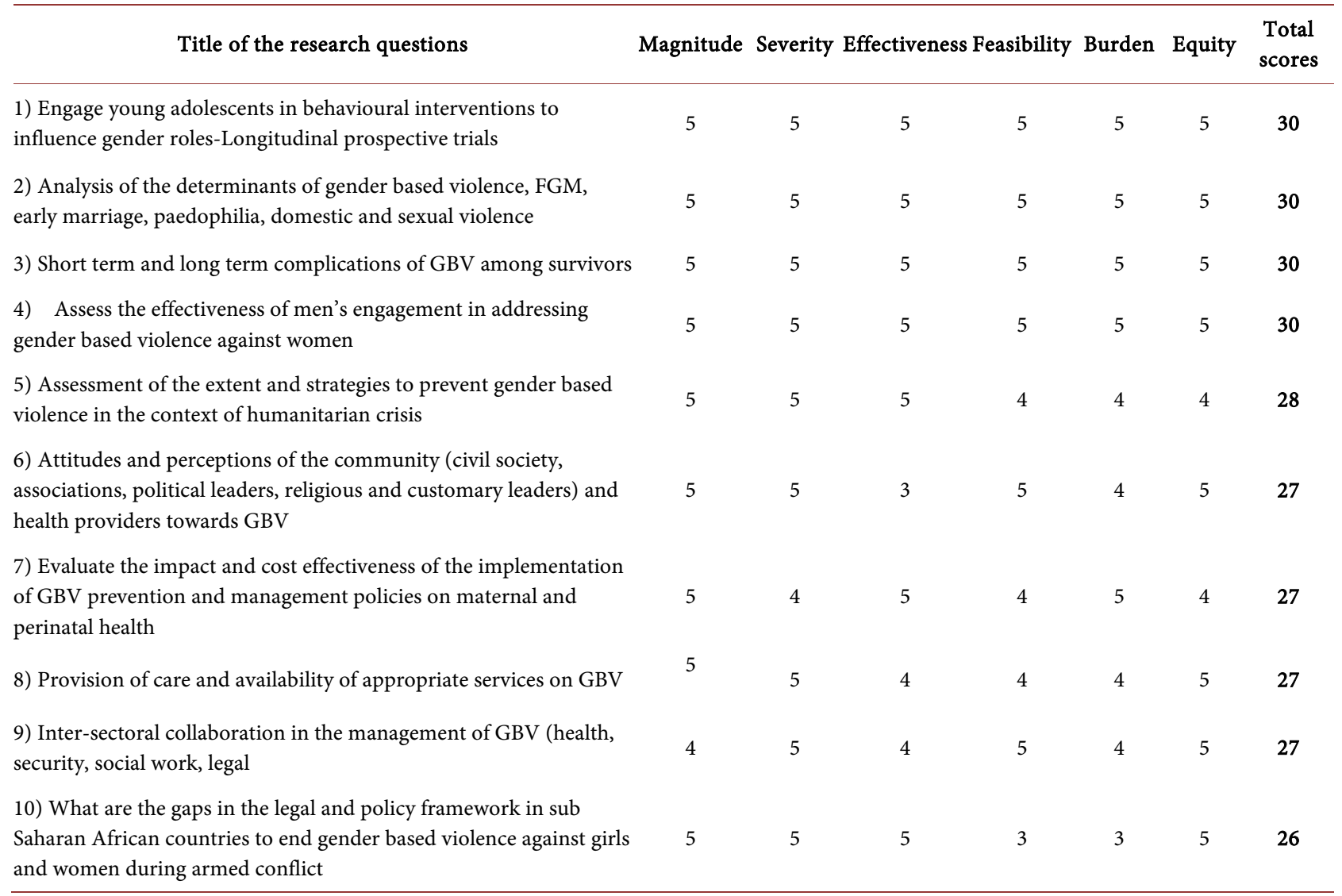

towards GBV", "evaluation of the impact and cost effectiveness of the implementation of GBV prevention and management policies on maternal and perinatal health"; "provision of care and availability of appropriate services on GBV" and "inter-sectoral collaboration in the management of GBV (health, security, social work, legal)". They all ranked highly including the last one at 26 points on the "gaps in the legal and policy framework in sub Saharan African countries to end gender based violence against girls and women during armed conflict".

\section{Discussion}

The research prioritization exercise aimed at filling in the research gaps by generating consensus on a set of questions that would guide researchers, policy makers and other interested stakeholders in addressing gender based violence in the WHO Africa Region.

The top priority research questions indicate the need for researches focusing on 1) Engaging young adolescents in behavioural interventions to influence gender roles-longitudinal prospective trials, 2) analyzing the determinants of gender based violence, FGM, early marriage, paedophilia, domestic and sexual violence 3) short term and long term complications of GBV among survivors and 4) assessing the effectiveness of men's engagement in addressing gender based violence against women. These results are consistent with other studies 
that have reported on research gaps on gender-based violence by Ali, M., Farron, M., Ouedraogo, L. et al. [15]. They note the need for addressing adolescent violence as a part of addressing GBV. These results also give impetus to the call by global partners on the call to action on protection of all from gender based violence.

Raising awareness using community based initiatives have proven to be successful in reducing incidences and mitigating the impact of GBV and changing attitudes, perceptions, knowledge and behavior [16]. Such techniques include the use of media such as radio, or specifically engaging men either through targeted "talks" or by organizing men's groups. It's therefore no surprise that men involvement against gender-based violence was among the top ranked priority research questions. Approaches such as engaging the community and men in non-threatening and non-divisive ways, whilst ensuring that awareness-raising activities are culturally sensitive and resonate with the realities of people's lives has been demonstrated to reduce GBV [17]. Community sensitization targeted at men and boys is important in tackling gender-based violence by changing attitudes and behaviour towards women.

Creating awareness on the root causes of GBV, promoting male leadership for GBV prevention through training with male community members and using male community leaders as advocates is encouraged. It is also important to recognize that programming targeted at women may have adverse effects on men's attitudes, and finding ways to include men appropriately in GBV programmes without reducing the focus on women or replicating gender inequalities is critical.

Involving youth and adolescents in behavioural interventions was also scored highly which is consistent with the fact that most gender-based violence is perpetrated by boys and men, therefore research that target and influences behavior of young adolescents are important. Programs focusing on men and boys include awareness raising and engagement activities, prevention pro-grams specifically for boys in middle and high school, and sexual violence prevention programs for men in postsecondary settings [18]. Increasing local knowledge, either the engagement of local/traditional service providers, such as community health workers, on GBV issues, or increasing community knowledge about the types of services available, and which services should be utilized after violence occurs, can enhance the understanding of the short and long term effect of gender-based violence.

The study had its strengths which included the validation processes at the various phases involving a wide range of experts from different organizations drawn from 16 countries thus a wider representation. There are also, however, limitations. While the CHRNI process is widely used, useful and practical, it also risks simplifying complex problems and only represents those who respond.

\section{Conclusion}

Gender based violence is increasingly recognized as public health issue that ad- 
versely affects the health of women and girls. While some progress has been realized in addressing GBV, the prevalence and impact makes it a significant issue to be addressed with sufficient evidence based interventions. This exercise provides a three-year investment case for research that could most effectively support interventions addressing gender based violence.

\section{Authors Contribution}

NT, OL, BF, MS, DK, DS, AC and EH conceptualized the idea of the research prioritization exercise. KC, AM, TL consolidated the online survey and provided technical support. All authors read and approved the final manuscript.

\section{Acknowledgements}

We thank all the experts who were involved in the research prioritization exercise for WHO Africa Region. They include: Zan Souleymane, Moufalilou Aboubakar, Bokossa Alexis Richard, Gaston D. Ahounou, Dina Gbenou, Hien Clotaire, Kiemtoré Sibraogo, Traoré Isidore Tiandiogo, Bassounda, Poïdigem, Dadjoari Moussa, Nguetabe Odile, Awad Adam Awad, Foumsou, Kini Brigitte Nsiku, Haimanot Ambelu Workineh, Tenaye Kebede, Girma Gemechu, Mekdes Daba, Deo Roseline, Samuel Oppong, Ivy Osei, Patrick K. Aboagye, Sy Telly, Férida Mara, Alpha Ahmadou Diallo, Tessougue Fatoumata, Idrissa Cissé, Sidy Diallo, Ben Moulaye Haidara, Moussa Kamissoko, Ojo Olumuyiwa, Ufere Joy, Ikpeze Okechukwu Christian, Chris Ega, Kabuteni Theopista John, Utumatwishima Jean Nepo, Ndaruhutse Victor, Ruzindana Kenneth, Mihretu Belete, Sithembile Dlamini-Nqeketo, K.S. Dithole, Rapinyana O., Ntombi Mtshali, Mercy Pindani, Azwihangwisi Helen Mavhandu-Mudzusi, Uta Lehmann, Boniface Ushie, David Norris, Blami Dao, Issiaka Sombie, Seni Kouanda, Richard Adanu, Goma Mboungou Mierette, Mavounia Ndoko Genil, Ngwenya, Mmamoitlamo and Mncwabe Pearl.

\section{Funding}

The WHO Regional office for Africa.

\section{Conflicts of Interest}

All authors declare no competing interests.

\section{References}

[1] UNFPA (2019) Supplement to Background Paper on Sexual and Reproductive Health Rights: An Essential Element of Universal Health Coverage. UNFPA, New York.

[2] UNFPA (2020) Nairobi Summit on ICPD 25: Accelerating the Promise. UNFPA, New York.

[3] WHO (2019) ICPD +25: A Renewed Commitment from WHO. WHO, Geneva.

[4] UNFPA (2010) Addressing Violence against Women and Girls in Sexual and Re- 
productive Health Services. New York.

[5] WHO (2019) Intimate Partner and Partner Violence against Women: Evidence. WHO, Geneva.

[6] Kosterina, E., Horne, S.G. and Lamb, S. (2019) The Role of Gender-Based Violence, Health Worries, and Ambivalent Sexism in the Development of Women's Gynaecological Symptoms. Journal of Health Psychology. https://doi.org/10.1177/1359105318825292

[7] World Health Organization (WHO) (2005) WHO Multi-Country Study on Women's Health and Domestic Violence against Women: Summary Report of Initial Results on Prevalence, Health Outcomes and Women's Responses. WHO, Geneva. http://www.who.int/gender/violence/who_multicountry_study/en/

[8] Campbell, J., Jones, A., Dienemann, J., et al. (2002) Intimate Partner Violence and Physical Health Consequences. Archives of Internal Medicine, 162, 1157-1163. https://doi.org/10.1001/archinte.162.10.1157

[9] Campbell, R., Lichty, L.F., Sturza, M. and Raja, S. (2006) Gynecological Health Impact of Sexual Assault. Research in Nursing \& Health, 29, 399-413.

https://doi.org/10.1002/nur.20155

[10] McCauley, H.L., Silverman, J.G., Decker, M.R., et al. (2015) Sexual and Reproductive Health Indicators and Intimate Partner Violence Victimization among Female Family Planning Clinic Patients Who Have Sex with Women and Men. Journal of Women's Health, 24, 621-628. https://doi.org/10.1089/jwh.2014.5032

[11] Golding, J., Taylor, D., Menard, L. and King, M.J. (2012) Prevalence of Sexual Abuse History in a Sample of Women Seeking Treatment for Premenstrual Syndrome. Journal of Psychosomatic Obstetrics and Gynaecology, 21, 69-80. https://doi.org/10.3109/01674820009075612

[12] Koepke, S., Eyssel, F. and Bohner, G. (2014) "She Deserved It": Effects of Sexism Norms, Type of Violence, and Victim's Pre-Assault Behavior on Blame Attributions toward Female Victims and Approval of the Aggressor's Behavior. Violence against Women, 20, 446-464. https://doi.org/10.1177/1077801214528581

[13] Lila, M., Gracia, E. and García, F. (2013) Ambivalent Sexism, Empathy and Law Enforcement Attitudes towards Partner Violence against Women among Male Police Officers. Psychology, Crime \& Law, 19, 907-919. https://doi.org/10.1080/1068316X.2012.719619

[14] Rudan, I., Chopra, M., Kapiriri, L., Gibson, J., Lansang, M.A., et al. (2008) Setting Priorities in Global Child Health Research Investments: Universal Challenges and Conceptual Framework. Croatian Medical Journal, 49, 398-408. https://doi.org/10.3325/cmj.2008.3.307

[15] Ali, M., Farron, M., Quedraogo, L., Mahaini, R.K., Miller, K. and Kabra, R. (2018) Research Gaps and Emerging Priorities in Sexual and Reproductive Health in Africa and Eastern Mediterranean Regions. Reproductive Health Journal, 15, Article No. 39. https://doi.org/10.1186/s12978-018-0484-9

[16] Souza, J.P., Widmer, M., Gülmezoglu, A.M., Lawrie, T.A., Adejuyigbe, E.A., Carroli, G., Crowther, C., Currie, S.M., Dowswell, T., Hofmeyr, J., et al. (2014) Maternal and Perinatal Health Research Priorities beyond 2015: An International Survey and Prioritization Exercise. Reproductive Health, 11, Article No. 6. https://doi.org/10.1186/1742-4755-11-61

[17] Holmes, R. and Bhuvanendra, D. (2014) Preventing and Responding to Gender-Based Violence in Humanitarian Crises. Commissioned and published by the Humanitarian Practice Network at ODI Number 77 January 2014. 
[18] Crooks, C.V., Jaffe, P., Dunlop, C., Kerry, A. and Exner-Cortens, D. (2019) Preventing Gender-Based Violence among Adolescents and Young Adults: Lessons from 25 Years of Program Development and Evaluation. Violence against Women, 25, 29-55. https://doi.org/10.1177/1077801218815778

\section{Abbreviations}

GBV: Gender based Violence; FGM: Female Genital Mutilation; CHNRI: Child Health and Nutrition Research Initiative; SRHR: Sexual and Reproductive Health and Rights; WHO: World Health Organization, STI: Sexually Transmitted infections. 